\title{
Research on the Countermeasures of Chinese University Graduates' Employment under the Social Security System
}

\author{
Zhen-yu YANG ${ }^{1, a}$ and Hong-guang $\mathrm{YE}^{2, \mathrm{~b},{ }^{*}}$ \\ 1,2Wuhan Textile University, Hubei, China \\ a845454681@qq.com, b836001463@qq.com
}

Keywords: Chinese university graduates, Employment, Social security, Unemployment.

\begin{abstract}
For Chinese university graduates' employment problem, using literature research, investigation method and comparative research, obtained a linkage by establish a mechanism for college students and the Department of labor. Using the social security to protect the College Students' employment and unemployment, effectively alleviate and even solve the employment problem of college students.
\end{abstract}

\section{Introduction}

In recently years, the number of Chinese universities' enrollment and graduation is rapidly growing. The unemployment of college graduates has become more and more serious. The existing social security system still has some shortages of employment and unemployment for college students. It still needs further improvement. This paper starting from the perspective of the social security, taking other countries' or regions' way in solving the problem of employment by social security for reference, making a series of analysis and putting forward some countermeasures to solve this problem. We hope it can play a valuable role.

\section{Discussions and Analyses}

As we all know, with the China university education from elite education to mass education, the number of college graduates increasing year by year. According to the statistics published by the statistical bulletin of national education development, the number of college graduates have increased from 4 million 130 thousand in 2006 to 7 million 490 thousand in 2015, the annual growth rate has increased more than $30 \%$. However, due to the speed of increasing new jobs that is existed for college graduates is still above the past average rate. From the aspect of employment rate, the annual employment rate float around $70 \%$ during 2001 to 2010. In 2014, the employment rate of college graduates after six months (92.1\%) rose slightly than in 2013 (91.4\%), compared with 2012 increased by $1.2 \%$. However, because of the base number is large every year, there still have lots of previous graduates and fresh graduate who cannot find a job. In 2010, for example, when the number of college graduates' employment has been more than seventy percent of the total number of graduates, compared with 2009 increased by about 4.2\%; Number of graduates' employment rose by more than 400,000 people, but there are still 1.75 million graduate at the status of job-waiting, combined with the previous college graduates' work is still not found, the number of unemployed graduates come to nearly 300 million in 2010 [1]. Therefore, China's college graduates' employment situation is not optimistic. Although, college graduates' employment and their comprehensive quality, school employment guidance has a close relationship. But from the aspect of whole college 
graduates, the author thinks that, in the view of college graduates' employment, social security system should be the most important factor in China's college graduates' employment.

\section{The Lacks of Social Security Efforts Seriously Affect College Students' Employment as a Whole}

Social security for the college students' employment system still has shortcomings. Because of the particularity of the college students, they are different from other unemployed personnel and unable to enjoy as well as their social security or basic life safeguard. The effects on college students' employment problem are very serious. Our country want to effectively solve the problem of employment of college graduates is faced with many difficulties. Adding students' groups into the old social security system of is not appropriate. Because of the particularity of the college students, that makes them different from general social workers, it is difficult to agree them on social security. Chinese social security system is still in the development of a sound stage, and cannot formed complete coverage. Such as less developed areas, rural or underemployed, and temporary employment, flexible employment or work unit level of development co., LTD. Cause life safeguard imperfect are more difficult to have an effective life safeguard or be involved in the phenomenon such as social security is not comprehensive. For unemployment insurance also needs attention, whether college students can get basic life safeguard rights and interests during the period of unemployment. As there is no work experience, students' groups are ineligible to enjoy fulfill capture to expend the qualify for the full year of unemployment insurance. In 2006, college students' unemployment registration system introduced strict, cumbersome procedures, low security funds caused extremely negative factors and it cannot achieve the effect. Taking the requirements of the notice as an example, unemployed college students need to register for the department of labor, the labor department of unemployed college students will arrange them to work first. If the arrangement is not appropriate, they should to accept the labor department's arrangement again, if it still not appropriate, the labor department issued only unemployment certificate. Unemployed college students after get unemployed proof against low condition to see whether they belong to, on to the streets to provide proof, residents' committees will investigate of the street. After investigation, upon the approval of the streets and "low" didn't apply for success after the civil affairs bureau of the public [2]. The cumbersome process result in that many poor college students is hard to get the subsidy in need. Therefore, college students establish and improve the unemployment insurance system is still a long way to go. However, if the group set up special security system for college students need to spend long time research and planning, demand for resources is very much too. The implementation is difficult.

\section{To Solve the Problem of Chinese College Students' Employment Based on the Social Security System}

The author thinks that, based on China's current social security system, the way to solve the problem of Chinese college students' employment from establishing perfect college students' employment and the labor department linkage mechanism and regulation of regional, industry between the two aspects of the differences of social security. 


\section{Establish a Perfect Mechanism of College Students' Employment and the Linkage of the Various Departments}

First, you need to improve the linkage of the university and the labor department. College graduates as a special employment group, just rely on the university itself or the labor department itself is difficult to solve the problem of university students' employment. Just rely on the university itself, not for the labor market to make a timely response to rapidly changing supply and demand environment, causes the information lag for university students' employment market has had a huge impact. Depend on the labor department provide a positive employment opportunities for college graduates employment problem solving is not enough, they cannot get the most direct for the work of college students' basic qualities, just rely on the appearance of the welfare can only solve the problem of university students' employment cannot effectively for the university students' employment problem from the source reasonable eradication. The existing social security system is imperfect, a lot of security does not cover or involves the students' groups, and lead to college students is difficult to guarantee the basic life.

Due to fresh graduates of colleges and universities have the most detailed information, so combining with the characteristics of colleges and universities should be to give students at graduation certain guidance and help, choose to offer some guidance for employment, conditional colleges and universities should also let the graduating college students to participate in practice activities, accumulate experience and practical technology in advance, after graduation can't adapt to the actual work of difficulties, to improve graduates employment rate, colleges and universities can help attract more excellent talents. By the labor department for university graduates to provide the appropriate selection of labor jobs and employment policy, while giving the labor market supply and demand change information in time. Colleges and universities should be aimed at this information to make a series of adjustment, such as there are differences in recruitment plan; Reasonable career planning and guidance; In view of the specialty practice the task ahead of time, such as effective help and guide the flow direction of employment and the guidance, to help college graduates before step into society can have certain social experience and work experience, to better fit into society after graduation. Build the linkage of the university and the labor department can make full use of its advantages.

Second, the recruitment unit and the linkage of the department of labor. As early as in 2011 the ministry of education set up "full service system of university students' employment" actively involved in the response of colleges and universities, colleges and universities with the enterprise or government, unit of choose and employ personal information exchanges and mutually, sharing the useful information effectively. The labor department should use their own advantages, and actively called for the recruitment unit into the campus recruitment, in addition to set up for graduation in university students' employment service professional functional department, also need condition of college students of different family or obstacles in life of college students to establish a targeted and professional department. For the labor department, need to establish a "labor department - school - unit" three-stage exchange information resource center, expand information sources and broad source of employment. Achieve full sharing effective personnel employment system, to facilitate the special circumstances of family information query, interactive information system and jobs. It is not hard to see from the above analysis, the regional colleges and universities graduate employment pressure and the characteristics of regional differentiation was significantly different reflected this factor of social 
security for the serious effect of the employment of university graduates. Only a comprehensive communication, can make the social security system is more complete and comprehensive, avoiding social security loopholes or not covered.

\section{Adjust the Regional Differences, Social Security between Industries}

Perfecting the social security system and the social welfare system is an important part to solve the problem of the employment of university graduates. It's important to reduce the city social security between urban and rural differences, efforts to close in the difference. Doing so can effectively avoid the situation of the lack of workplace. College graduates as new employment group, is lack of experience, etc. That needs to be given the right guidance. Social security for the employment of college students and college students' unemployment cushion "safety zone" to maintain social stability and security of sustainable social and economic growth, with the growth to perfect the social welfare and social security, such a process of constant not only can make the virtuous cycle of conducive to a steady development of the society, but also can effectively alleviate the plight of university students' employment and pressure. Through a complete social security system security and encourage students to take an active part in all kinds of work, around the equilibrium and differences between regional and industry development. Attaches great importance to the poor social security system or security level lower regions and industries, we will increase support for these areas or industry, to safeguard employment population balance between regional and industry. For university graduates to provide $1 \sim 2$ years paid monthly basic life safeguard, remains the same, the first year in the second year of decline from month to month to stimulate the students to find a job as soon as possible, the amount by regional economic development level, consumption level, factors such as joint action [3]. This guarantee both college students graduate and find a job when faced to the question about basic life demand. It can strengthen the courage of the college students about looking for jobs and can also stimulated the confidence of the students to make them actively to look for a job. Perfect social security system can effectively increase college students' employment confidence and security as well as reduce their puzzled and upset sense [4]. The government should make the social security fund raise mechanism more perfectly, and to ensure the sufficient funds about university students' employment in the construction of social security business. To a certain extent, the situation of social security conditions in various regions of the imbalance play a moderating role.

\section{Corresponding Security Policy for College Students' Entrepreneurship}

For entrepreneurship attaches great importance to in recent years, countries, put forward the "public entrepreneurship, peoples' innovation", There are lots of university graduates group has ambitious about entrepreneurship. The author thinks that, it shall timely make for entrepreneurial students' groups of social security system, The government should to encourage college students' self-employment activities, make college graduates in the initial period of self-employment and have no trouble back at home, safely to entrepreneurial activity, effectively and encourage entrepreneurship to create more employment opportunities. Not only to make the material, spirit, self-triple combined incentives, encourage entrepreneurship to create more employment opportunities and economic development, but also can improve the ability of independent innovation. It can easily get full of benefits. 


\section{Conclusions}

This papers though the domestic and foreign study on the influence of the university students' employment in social security. To get more detailed from the point of view of social security to explore the causes of college students' employment problem, integrated all the data is putting forward and using the way that schools, the labor department and recruitment departments' linkage. Using their own advantages to strengthen college students' information and recruitment information timeliness and immediacy between different regions and industries. To adjust the differences between different area and to pay more attention to the guarantee of entrepreneurship students. Through such three improvements, the growth of employment pressure year by year in our country can be effectively alleviated. It will provide a solution on the question of the university students' unemployment.

\section{References}

[1] Mou Lina, Self-employment continues to rise at the beginning of the "center of gravity down" trend-Chinese college graduates' employment report - 2015, Atlantic Weekly, 2015.7.30.(In Chinese)

[2] Zheng Gongcheng, The two themes of the Chinese democracy: Social security and employment, Theoretical discussion, 2004(05)47. (In Chinese)

[3] Liu Pu. The establishment and improvement of the social security system of College Students' Employment, vision, research on continuing education, 2010(12)69-70. (In Chinese)

[4] Gai Hongwei, Liu Wei. Research on social security perspective college graduates' employment problem in China, Chinese collective economy, 2015(19)152. (In Chinese) 